\title{
MODELLING OF REFLECTIVITY IN 1D POROUS SILICON PHOTONIC CRYSTAL
}

\author{
M. Beresna ${ }^{\mathrm{a}}$, R. Tomašiūnas ${ }^{\mathrm{a}}, \mathrm{J}$. Volk ${ }^{\mathrm{b}}$, and G. Kadar $^{\mathrm{b}}$ \\ ${ }^{a}$ Institute of Materials Science and Applied Research, Vilnius University, Sauletekio 10, LT-10223 Vilnius, Lithuania \\ E-mail: martynas.beresna@ff.vu.lt \\ ${ }^{\mathrm{b}}$ Research Institute for Technical Physics and Materials Science of the Hungarian Academy of Sciences, Konkoly Thege \\ Miklos 29-33, H-1121 Budapest, Hungary
}

Received 13 July 2007; revised 5 October 2007; accepted 21 November 2007

\begin{abstract}
In this study we present two different ways - direct spectra calculation via transfer matrix method (TMM) and structure reconstruction via optimization technique - for analysing a porous silicon Fabry-Perot resonator. As-prepared and aged cases of the structure are considered. The models used account for oxidation and dispersion of materials. Obtained fits are also demonstrated and discussed.
\end{abstract}

Keywords: porous silicon, refractive index, Bragg grating, photonics

PACS: 42.25.Bs, 42.70.Qs, 68.65.Ac

Porous silicon multilayered structures [1,2] or Bragg gratings are appealing devices for their potential application as chemical detectors, since optical characteristics like reflectance spectra are highly sensible to chemical impact [3-5]. More sophisticated applications include second harmonic generation [6], improvement of porous silicon emission properties [7]. Being sponge-like material porous silicon also undergoes spontaneous degradation process, with oxidation predominating. Mostly porous silicon multilayers are analysed as prepared, while aged case is rather poorly studied. On the other hand, considering applications of such structures the degradation processes should be considered, whether they should be avoided or they should be thoroughly analysed. In other publications porous silicon is considered as a non-dispersive material. In the present work we reconstruct porous silicon 1D photonic crystal's composition by modelling its reflectance spectrum. We have taken into account porous silicon dispersion and spontaneous oxidation. Modelling is performed using the transfer matrix method (TMM) and a commercial software package Optilayer. This can be an effective way of evaluating ageing processes in every particular case.

In our case we deal with porous silicon Fabry-Perot resonator, the scanning electron microscopy (SEM) microphotograph of which is shown in Fig. 1. Layers with different porosity can be clearly distinguished.

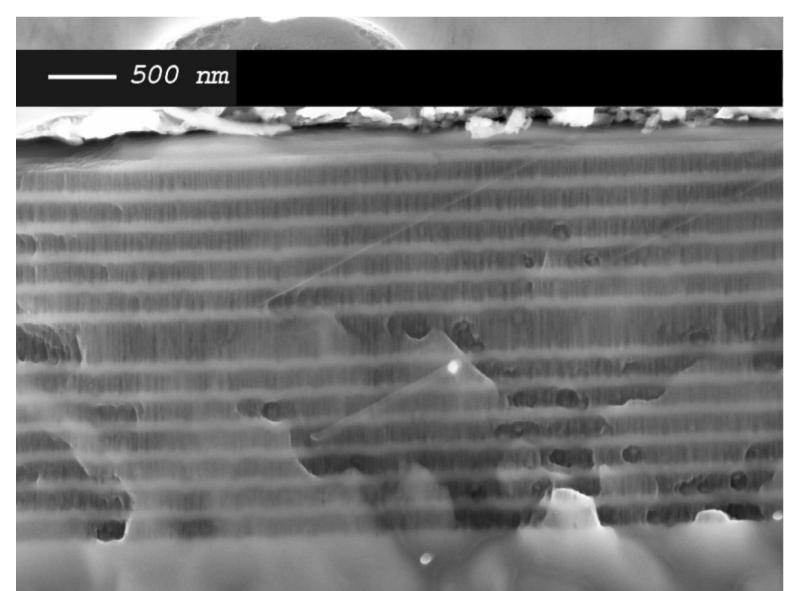

Fig. 1. SEM micrograph of porous silicon multilayered structure.

The porosity alternation gives the periodic change of medium effective refractive index. Spectral characterization (Fig. 2) of the sample shows blue shift of the whole spectrum comparing the as-prepared to aged condition. Also a cavity resonance, observed inside the "forbidden" band, becomes less expressed and wider.

For numerical analysis of the structure we have chosen transfer matrix method [8,9], which is mostly used for solving one-dimensional photonic problems. The idea is to describe each layer with a $2 \times 2$ matrix, which comes from boundary conditions for electromagnetic field. The product of matrices can be considered as an operator describing the effect of the whole structure on 


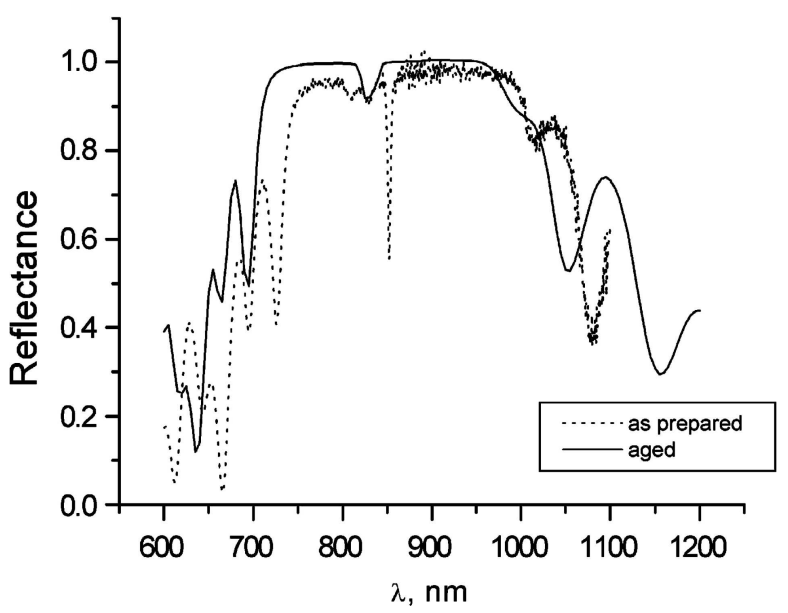

Fig. 2. Measured spectral characteristics of porous silicon FabryPerot resonator. As-prepared and aged states.

electromagnetic field. In the case of one layer we will have:

$$
\begin{aligned}
& \left(\begin{array}{c}
1 \\
n_{\mathrm{I}}
\end{array}\right)+\left(\begin{array}{c}
1 \\
-n_{\mathrm{I}}
\end{array}\right) \frac{E_{\mathrm{R}}}{E_{\mathrm{I}}}= \\
& \left.k \begin{array}{cc}
\cos k d & -\frac{\mathrm{i}}{n_{1}} \sin k d \\
-\mathrm{i} n_{1} \sin k d & \cos k d
\end{array}\right)\left(\begin{array}{c}
1 \\
n_{\mathrm{T}}
\end{array}\right) \frac{E_{\mathrm{T}}}{E_{\mathrm{I}}}, \\
& k=\frac{2 \pi n_{1}}{\lambda},
\end{aligned}
$$

where $n_{\mathrm{I}}, n_{1}, n_{\mathrm{T}}$ are refractive indices of media through which passes incident, in-layer, and transmitted radiation, respectively. $E$ denotes an electric field in corresponding media, $k$ is a wave number, $d$ is the thickness of the layer, and $\lambda$ is a wavelenght at which the reflectance is calculated. The $2 \times 2$ matrix shown above is the transfer matrix of the $i$ th layer, later it will be denoted as $M_{i}$. Now in the case of multilayered structure we will have $M=M_{1} \cdot M_{2} \cdot \ldots \cdot M_{N}$, which is transfer matrix of the whole structure. After introducing the reflection and transmission coefficients $r$ and $t$, it can be written:

$$
\left(\begin{array}{c}
1 \\
n_{\mathrm{I}}
\end{array}\right)+\left(\begin{array}{c}
1 \\
-n_{\mathrm{I}}
\end{array}\right) r=M\left(\begin{array}{c}
1 \\
n_{\mathrm{T}}
\end{array}\right) t
$$

$$
\begin{aligned}
& \text { If } M=\left(\begin{array}{ll}
A & B \\
C & D
\end{array}\right) \text { then } \\
& \quad r=\frac{A n_{\mathrm{I}}+B n_{\mathrm{T}} n_{\mathrm{I}}-C-D n_{\mathrm{T}}}{A n_{\mathrm{I}}+B n_{\mathrm{T}} n_{\mathrm{I}}+C+D n_{\mathrm{T}}}, \\
& t=\frac{2 n_{\mathrm{I}}}{A n_{\mathrm{I}}+B n_{\mathrm{T}} n_{\mathrm{I}}+C+D n_{\mathrm{T}}},
\end{aligned}
$$

Table 1. Refractive indices calculated in non-dispersive case using the Bruggemann equation.

\begin{tabular}{cccccc}
\hline$\varepsilon$ & $\varepsilon_{\mathrm{M}}$ & $d, \mathrm{~nm}$ & $f$ & $\varepsilon_{\text {eff }}$ & $n$ \\
\hline \multirow{2}{*}{12.82} & \multirow{2}{*}{1} & 93 & 0.505 & 4.71 & 2.17 \\
& & 173 & 0.795 & 1.80 & 1.34 \\
\hline
\end{tabular}

Finally, the reflectance $R$ is given by $R=|r|^{2}$. The relation between porosity and the effective dielectric function can be approximately described by the Bruggemann equation:

$$
f \frac{\varepsilon-\varepsilon_{\mathrm{eff}}}{\varepsilon+2 \varepsilon_{\mathrm{eff}}}+(1-f) \frac{\varepsilon_{\mathrm{M}}-\varepsilon_{\mathrm{eff}}}{\varepsilon_{\mathrm{M}}+2 \varepsilon_{\mathrm{eff}}}=0
$$

where the quantity $f$ indicates the volumetric fraction, $\varepsilon$ and $\varepsilon_{\mathrm{M}}$ are the dielectric functions of $\mathrm{Si}$ and of the embedding medium (air), whereas $\varepsilon_{\text {eff }}$ is the effective dielectric function of porous silicon.

Initially we analysed the as-prepared case. Knowing the porosity of each layer we calculated refractive indices (Table 1) according to the Bruggemann equation and later the reflectance spectrum. The problem was simplified by taking only real part of the complex indices of refraction $\left(\sqrt{\varepsilon}=n^{*}=n\right.$ and $\left.k=0\right)$.

We examined both the dispersive and non-dispersive case (Fig. 3). Porous silicon dispersive properties were assumed to be brought about only by silicon. The dispersion of silicon was assumed to have an exponential form. There is almost no difference between both mentioned cases at longer wavelengths. However, on the blue side of spectrum discrepancies are much larger, as dispersion curve begins to steepen. In the dispersive case the position of the calculated resonance peak is in good coincidence with the measured one.

The blue shift observed in the aged structure's spectrum is explained as a feature of oxidation of silicon (Fig. 1). It is notable that layers possessing higher porosity oxidize more [10], since higher porosity means a larger internal surface as well, thus leading to higher chemical reactivity. The oxidation process seems to be homogenous, as it has been indicated by RBS (Rutherford backscattering spectroscopy) characterization performed on similar structures [11]. The oxide has lower refractive index than pure silicon. Thus the oxidation process changes the effective refractive index of each layer. In order to account for the influence of silicon dioxide, we have to consider porous media made of three materials: silicon, silica, and air. In this case the Bruggemann equation is

$$
f \frac{\varepsilon-\varepsilon_{\mathrm{eff}}}{\varepsilon+2 \varepsilon_{\mathrm{eff}}}+f_{\mathrm{M}} \frac{\varepsilon_{\mathrm{M}}-\varepsilon_{\mathrm{eff}}}{\varepsilon_{\mathrm{M}}+2 \varepsilon_{\mathrm{eff}}}+f_{\mathrm{int}} \frac{\varepsilon_{\mathrm{int}}-\varepsilon_{\mathrm{eff}}}{\varepsilon_{\mathrm{int}}+2 \varepsilon_{\mathrm{eff}}}=0,
$$



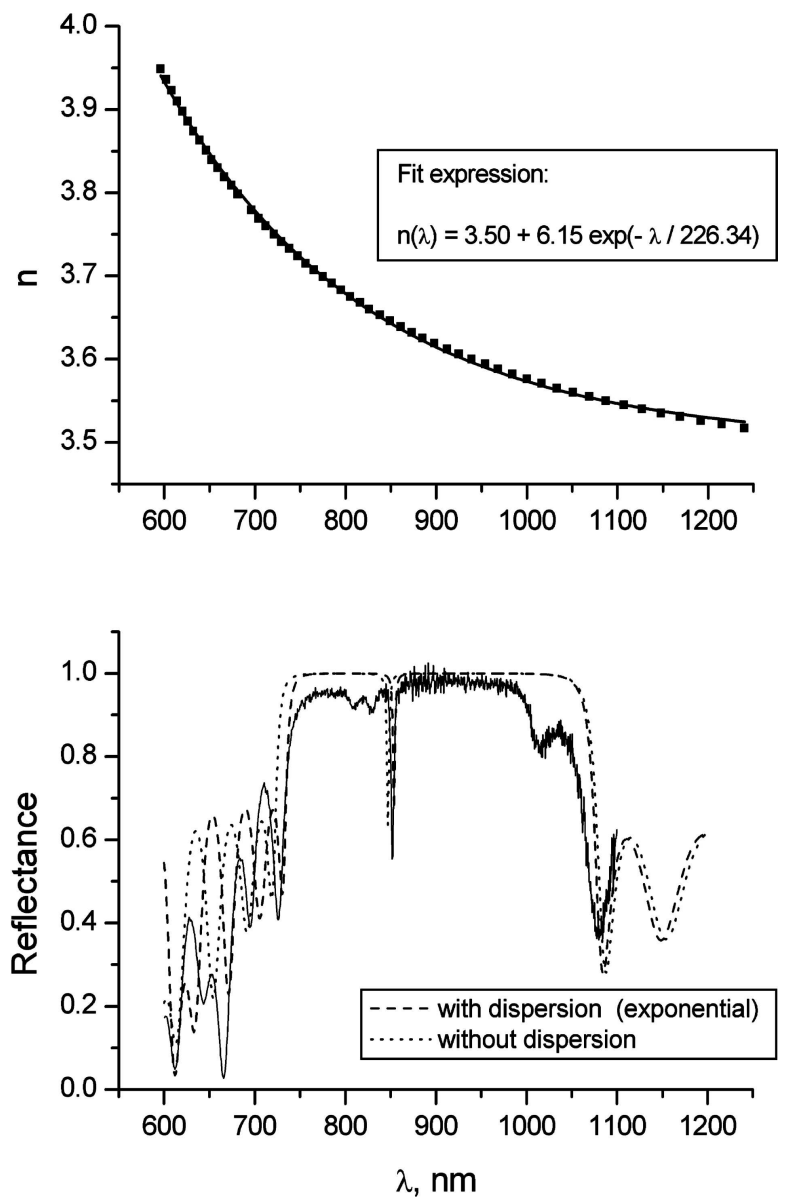

Fig. 3. Spectrum fits made with TMM using non-dispersive and dispersive models of as-prepared structure. Experimental silicon dispersion curve [14] (top) and its best fit (expression given in insert).

$$
f+f_{\mathrm{M}}+f_{\mathrm{int}}=1 .
$$

Obviously, volumetric fractions of silicon and air are lower than initial ones. Mostly the silicon volumetric fraction is changed; porosity (or fraction of air) is also slightly decreased due to expansion caused by oxidation. These two changes have opposite impact on the spectrum shifting, as the refractive index of silicon dioxide is between those of silicon and air. Still, the blue shift, which occurs due to silicon replacement with silicon dioxide, is predominating. Taking this into account in our modelling we analysed only reduction of silicon volumetric fraction (Fig. 4). The best fits were obtained by assuming oxide volumetric fraction for high index layers 0.010 , and for low index layers 0.065 ; for resonant layer it was 0.015 . Oxidation of low index layers affects more the left-hand side of the spectrum, while high index layers are more responsible for the right-hand side of the spectrum. Of course, the resonance peak is mostly susceptible to the refractive index of resonant layer. Despite large discrepancies on
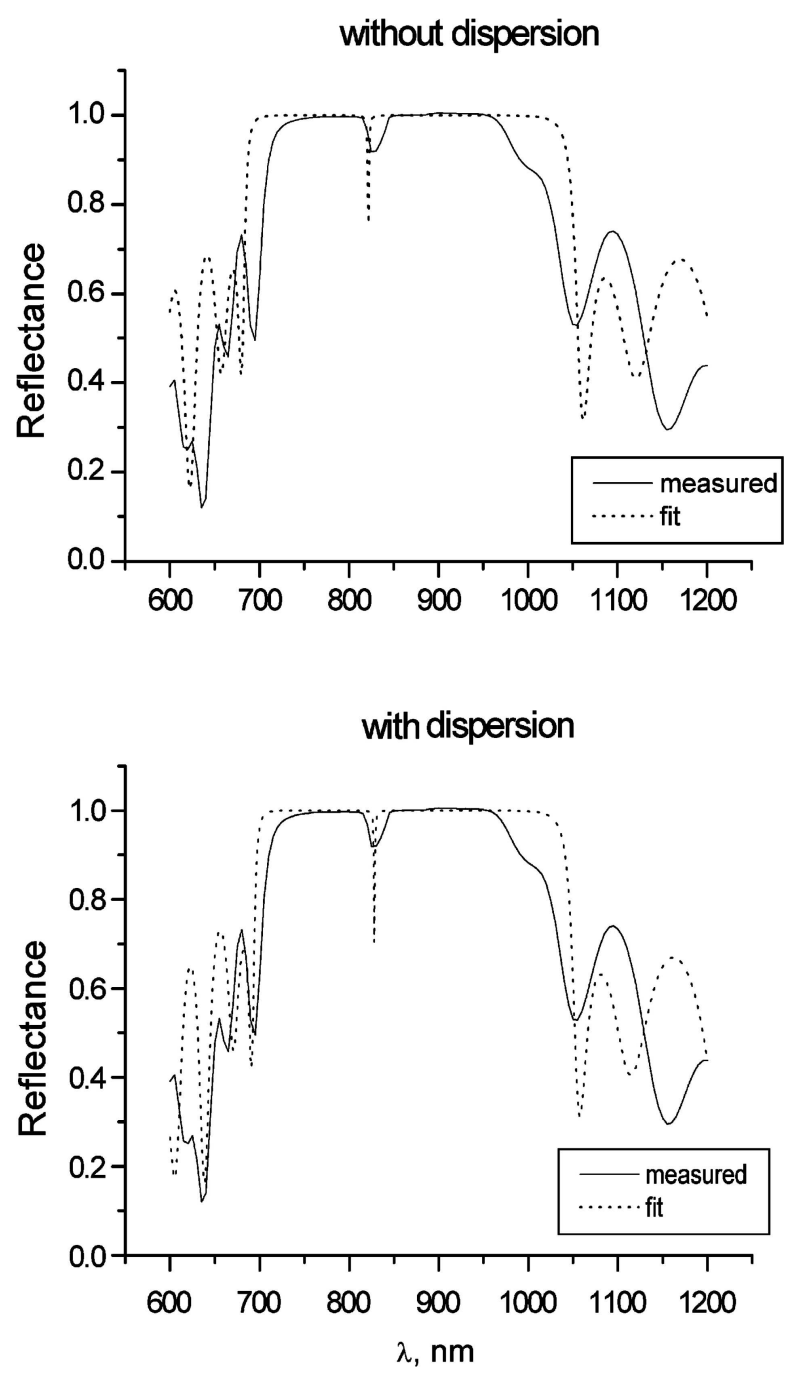

Fig. 4. Degraded multilayer's spectrum fits made using TMM. Non-dispersive (above) and dispersive (below) cases. Expression of dispersion the same as in Fig. 3.

both sides of band gap, the fringes of measured spectrum and modelled one looks similar.

There is an alternative way of solving such inverse problems, i.e. the structure reconstruction from measured scattering data. Several algorithms are currently developed $[12,13]$. All of them rely on optimization methods. The idea is to comprise a function dependent on measured reflectance and one that has to be calculated. By searching for a global minimum the structure is reconstructed, i.e. the refractive index and thickness of each layer can be obtained. There are high chances to fall into a local minimum during optimization procedure as the optimized function depends on many variable parameters. Such methods still require good knowledge of initial conditions (assumed refractive indices and thicknesses) in order to obtain reliable results. As an example we have tried commercial 
Optilayer package, where a program designed for analysis of multilayered structures is included.

First we assumed that thicknesses of layers are asgrown. In this case, no acceptable fit was obtained. The modelling results were close to measured ones when discrepancies in thickness, dispersion of refractive indices were taken (Fig. 5). It can be seen that fringes coincide except for the resonance peak. The fit can be regarded as having reliable physical meaning. High porosity layers undergo greater changes than those of low porosity. Physically such great changes in thickness could not be expected. Of course, optical properties of the structure are defined through the layer's optical path which is a combination of the refractive index and physical length (i.e. the thickness). As the model made on Optilayer was restricted to variation of only two values of refractive index (for high and low porosity), the optimization algorithm had to change thicknesses in order to obtain a better fit of spectrum. We have made the above-mentioned restrictions to avoid falling into a local minimum, as allowing the independent reconstruction of all layers most often leads to local minima and meaningless solutions.

In conclusion, we have demonstrated two different ways of porous silicon multilayer spectral analysis. It was shown that a more comprehensive model could be obtained, once dispersion included. The observed structure's ageing was successfully explained by partial silicon oxidation. By fitting a measured spectrum of aged structure, we evaluated the oxidation degree of our structure. Higher porosity layers became more oxidized than low porosity ones, as expected. Distribution of layers' thicknesses obtained solving optimization problem implies randomness, which stems either from preparation process or oxidation.

\section{Acknowledgements}

The authors thank R. Buzelis for the spectral measurements, Optida Co Ltd. for providing access to Optilayer software package. This work was supported in part by the Agency for International Science and Technology Development Programmes in Lithuania and EU COST P11 Action.

\section{References}

[1] G. Vincent, Optical properties of porous silicon superlattices, Appl. Phys. Lett. 64, 2367-2369 (1994).
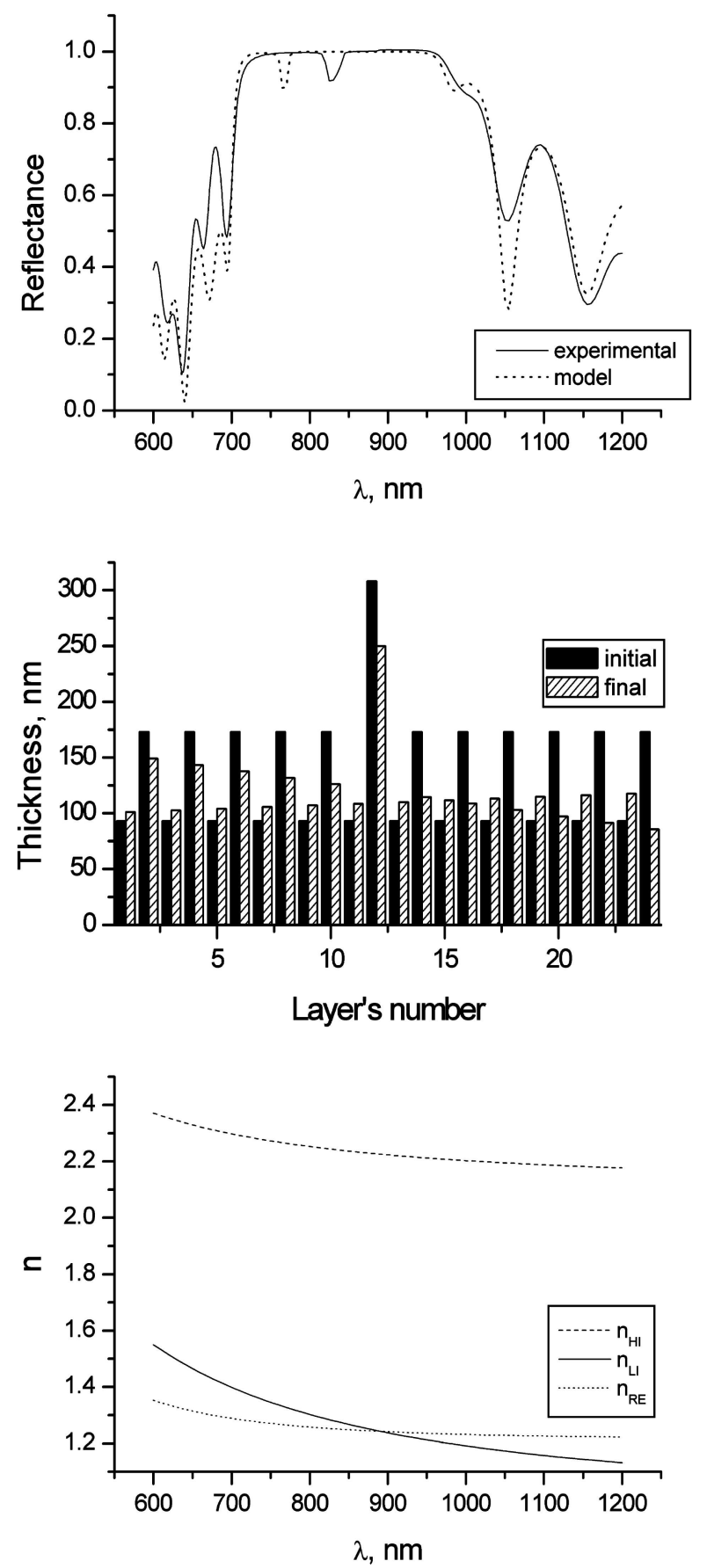

Fig. 5. Fitting results obtained using commercial Optilayer package. The best fit of measured spectrum (top). In the middle new thicknesses of layers obtained during optimization procedure are shown. The initial ones are also presented for comparison. Dispersion curves evolved from the same procedure are given at bottom $\left(n_{\mathrm{HI}}\right.$ high refractive index, $n_{\mathrm{LI}}$ low refractive index, $n_{\mathrm{RE}}$ refractive index of resonator).

[2] C. Mazzoleni and L. Pavesi, Application to optical components of dielectric porous silicon multilayers, Appl. Phys. Lett. 67, 2983-2985 (1995).

[3] J. Volk, T. Le Grand, I. Barsony, J. Gombkötő, and J.J. Ramsden, Porous silicon multilayer stack for sen- 
sitive refractive index determination of pure solvents, J. Phys. D 38, 1313-1317 (2005).

[4] P.A. Snow, E.K. Squire, and P.St.J. Russell, Vapor sensing using the optical properties of porous silicon Bragg mirrors, J. Appl. Phys. 86, 1781-1784 (1999).

[5] V. Mulloni and L. Pavesi, Porous silicon microcavities as optical chemical sensors, Appl. Phys. Lett. 76, 2523-2525 (2000).

[6] T.V. Dolgova, A.I. Maidykovski, M.G. Martemyanov, A.A. Fedyanin, G. Marowsky, V.A. Yakovlev, and G. Mattei, Giant microcavity enhancement of secondharmonic generation in all-silicon photonic crystals, Appl. Phys. Lett. 81, 2725-2727 (2002).

[7] L. Pavesi and V. Mulloni, All porous silicon microcavities: Growth and physics, J. Lumin. 80, 43-52 (1999).

[8] P. Yeh, A. Yariv, and C.-S. Hong, Electromagnetic propagation in periodic stratified media. I. General theory, J. Opt. Soc. Am. 67, 423-438 (1977).

[9] M. Born and E. Wolf., Principles of Optics, 7th ed. (Cambridge University Press, 1999).
[10] O. Bisi, S. Ossicini, and L. Pavesi, Porous silicon: A quantum sponge structure for silicon based optoelectronics, Surf. Sci. Rep. 38, 1-126 (2000).

[11] V. Torres-Costa, F. Pászti, A. Climent-Font, R.J. Martín-Palma, and J.M. Martínez-Duart, Optical and in-depth RBS characterization of porous silicon interference filters, J. Electrochem. Soc. 152, 846-850 (2005).

[12] R.T. Zheng, N.Q. Ngo, L.N. Binh, S.C. Tjin, and P. Shum, Optimization technique for simple reconstruction of the index modulation profile of symmetric fiber Bragg gratings from their reflective spectrum, Opt. Eng. 45, 014403-1-4 (2006).

[13] F. Lhommé, Ch. Caucheteur, K. Chah, M. Blondel, and P. Mégret, Synthesis of fiber Bragg gratings parameters from experimental reflectivity: A simplex approach and its application to the determination of temperaturedependent properties, Appl. Opt. 44, 493-497 (2005).

[14] Properties of Silicon (INSPEC, Gresham Press, Surrey, 1988).

\title{
AKYTO SILICIO VIENMAČIO FOTONINIO KRISTALO ATSPINDŽIO MODELIAVIMAS
}

\author{
M. Beresna ${ }^{\mathrm{a}}$, R. Tomašiūnas ${ }^{\mathrm{a}}, \mathrm{J}$ Volk $^{\mathrm{b}}, \mathrm{G}$ Kadar $^{\mathrm{b}}$

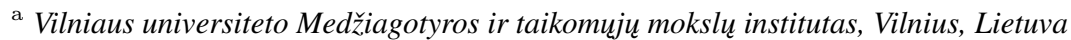 \\ ${ }^{\mathrm{b}}$ Vengrijos mokslı akademijos Techninès fizikos ir medžiagotyros institutas, Budapeštas, Vengrija
}

\section{Santrauka}

Pateikti du matematiniai modeliai, skirti tirti vienmačio fotoninio kristalo optines savybes: pernašos matricos metodas ir optimizavimo algoritmas. Jie taikyti nustatant tiriamo fotoninio kristalo sluoksnių storius ir jų lūžio rodiklius pagal išmatuotą atspindžio spektrą. Nagrinèti ir ką tik pagaminto, ir oksidavusio darinio atvejai. Modeliuojant buvo îvertinta dispersijos įtaka atspindžio savybėms, parodyta, kad oksidacija sparčiau vyksta labiau akytame silicyje. Oksidacija taip pat lemia atspindžio spektro poslinki i trumpesnių bangos ilgių srití. 